\title{
Altered thresholds for thermoregulatory sweating and vasodilatation in anorexia nervosa
}

\author{
PETER LUCK， ANTHONY WAKELING
}

\section{Summary and conclusions}

The changes in peripheral (hand) blood flow that occurred when deep body temperature was raised were measured in 13 patients with anorexia nervosa and 13 control subjects. The relation between blood flow and core temperature was shifted to the left in the patients with anorexia, with the onset of vasodilatation occurring at lower core and mean skin temperatures: no significant differences in the slopes of the responses were evident. The onset of thermal sweating occurred at lower core and mean skin temperatures in the patients with anorexia than in the controls. After ingestion of a highenergy liquid meal core temperature increased in the patients, and this was accompanied by a significant rise in peripheral blood flow in most cases. A similar meal in the normal subjects was followed by either no change in core temperature or a slight fall, and no consistent change in peripheral blood flow.

These findings suggest that the lowering of thresholds for thermoregulatory sweating and vasodilatation may be a contributory factor to the abnormally low core temperature of patients with anorexia and may also explain some of their common complaints relating to feelings of warmth in the hands and feet after meals.

\section{Introduction}

Much recent work on anorexia nervosa has been directed towards examining whether the illness might be partly due to a disorder of hypothalamic function. The strongest evidence in support of this hypothesis derives from studies of the endocrine state of patients with anorexia nervosa. ${ }^{1}$ Since the observation by Mecklenburg et al, ${ }^{2}$ however, that anorectic patients exposed to extremes of environmental temperatures show exaggerated fluctuations in core temperatures, the concept that thermoregulatory disturbances may be another manifestation of hypothalamic dysfunction in these patients has gained some credence. In addition to the obvious physiological relevance in patients functioning on the verge of hypothermia, such central disturbances may be important in perpetuating their eating disorders, since many complain of excessive feelings of heat (both centrally and peripherally) after a meal, together with abnormal sweating and palpitations. In the present study we compared the thermoregulatory responses of anorectic patients with those of normal subjects in an attempt to investigate further this possibility of a central thermoregulatory disturbance in the disease.

\section{Subjects and methods}

We studied 13 patients, who all conformed to the diagnostic criteria of anorexia nervosa formulated by Russell. ${ }^{3}$ Ten were adolescent, postpubertal girls of mean age 16 , two were adolescent youths,

\section{Royal Free Hospital, London NW3 2QG}

PETER LUCK, MA, MB, lecturer, department of physiology

ANTHONY WAKELING, PHD, FRCPSYCH, professor, academic department of psychiatry and one was a woman aged 34 years with a history of anorexia nervosa of many years' duration. The average weight of the patients was $35 \mathrm{~kg}$. All had been admitted to hospital in a malnourished state and were treated by intensive nursing care aimed at persuading them to achieve a high energy intake, and supportive psychotherapy. By the time of testing they were all eating full meals and none had taken medication. Thirteen healthy medical students ( 11 women, two men) served as controls. Their mean weight was $59 \mathrm{~kg}$ and mean age 20 years. None was receiving any medication at the time of the tests.

All the patients were tested within seven days after admission to the acute psychiatric ward. Each study was conducted at about 900 am in a room whose temperature was controlled $\left(20+1^{\circ} \mathrm{C}\right.$ ambient $)$, with the subject lightly clad after an overnight fast. Part 1 of the study was performed on all 26 subjects; only 10 from each group participated in part 2. The two parts of the study were performed on different days in each case.

In part 1 the following measurements were obtained after the subject had lain quietly for 30 minutes: initial hand blood flow using venous occlusion plethysmography ${ }^{4}$; initial core temperature using a sublingual thermistor (Light Laboratories) read to $0 \cdot 1^{\circ} \mathrm{C}$; and initial mean skin temperature using weighted readings from six cutaneous sites according to the method of Palmers and Park. ${ }^{5}$ Both legs were then immersed to upper calf level in stirred water at $42( \pm 0.5)^{\circ} \mathrm{C}$ and the above measurements repeated at half-minute intervals. The onset of forehead sweating was noted by the appearance of purple specks on iodine-impregnated paper applied to the skin. The test was stopped when there was no further rise in hand blood flow and forehead sweating was apparent.

In part 2 the following measurements were made, again after the subject had lain quietly for 30 minutes: core temperature using a sublingual thermistor; heart rate using a Brobeck cardiotachometer; and initial hand blood flow using venous occlusion plethysmography. A liquid meal containing Complan $130 \mathrm{~g}$ and lactose $40 \mathrm{~g}$ (to provide protein $26 \mathrm{~g}$, fat $20 \mathrm{~g}$, and carbohydrate $109 \mathrm{~g}$ ) made up with $250 \mathrm{ml}$ water at the subject's core temperature was then administered and the above measurements repeated at five-minute intervals for 90 minutes.

Core temperature was assessed with a sublingual thermistor. Care was taken to ensure that the thermistor was kept under the tongue and that the mouth remained closed. The optimal site for estimation of core temperature is highly controversial, and none of the three currently favoured sites - that is, rectal, tympanic membrane, and oesophageal-were readily acceptable to the anorectic patients. Weight loss in these patients might be associated with loss of thermal insulation in the mouth producing erroneously low values of core temperatures estimated at the sublingual site. In a preliminary study of five patients with anorexia whose mean body weight was $28 \%$ below that of a matched group of controls, however, the mean difference between rectal and sublingual temperatures in the patients did not differ significantly from that in the control group. This suggests that using sublingual temperature as an index of core temperature is as valid for malnourished as for normal subjects.

\section{Results}

Table I shows the results of part 1 of the study. Vasodilatation was arbitrarily considered to have occurred when flow had increased to three times the initial value, and mean skin and core temperatures are given for this point. All variables in part 1 showed a significant difference between the patients and controls except the initial mean skin temperature, the mean maximal flow, and $\alpha$ (the mean of the slopes of the responses normalised to a flow of $8 \mathrm{ml} / \mathrm{min} / 100 \mathrm{ml}$ and a mean skin temperature of $33^{\circ} \mathrm{C}$, calculated according to the method of Wenger et $a l^{6}$ ).

Figure 1 shows the relation between core temperature and peripheral flow in all 26 subjects studied, while figure 2 shows the core and skin temperatures at the onset of forehead sweating for all the subjects. 
TABLE I-Temperature and peripheral circulatory responses to thermal stress in the patients and controls

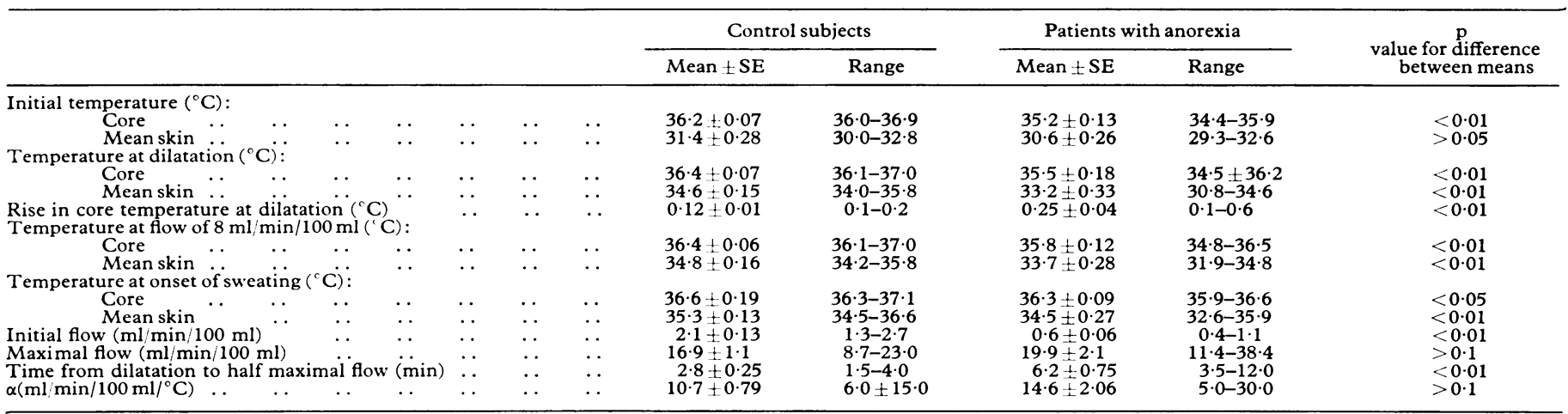

TABLE II-Changes in core temperature, peripheral flow, and heart rate after liquid meal

\begin{tabular}{|c|c|c|c|}
\hline & $\begin{array}{c}\text { Change } \\
\text { in core temperature } \\
\left({ }^{\circ} \mathrm{C}\right)\end{array}$ & $\begin{array}{l}\text { Ratio of } \\
\text { postprandial to } \\
\text { initial flow }\end{array}$ & $\begin{array}{l}\text { Rise } \\
\text { in heart rate } \\
\text { (beats } / \mathrm{min} \text { ) }\end{array}$ \\
\hline \multicolumn{4}{|c|}{ Control subjects } \\
\hline $\begin{array}{l}\text { Mean! SE } \\
\text { Range }\end{array}$ & $\begin{array}{l}-0 \cdot 2-0.05 \\
(-0 \cdot 4)-(0+1)\end{array}$ & $\begin{array}{l}0.08+0.09 \\
0.3-1 \cdot 2\end{array}$ & $\begin{array}{l}9 \cdot 6+1 \cdot 03 \\
5-15\end{array}$ \\
\hline \multicolumn{4}{|c|}{ Patients with anorexia } \\
\hline $\begin{array}{l}\text { Mean : SE } \\
\text { Range }\end{array}$ & $\begin{array}{l}0 \cdot 3=0.02 \\
0 \cdot 2-0 \cdot 4\end{array}$ & $\begin{array}{l}3.5+0.6 \\
0.9-6.6\end{array}$ & $\begin{array}{l}8 \cdot 6 \cdot 1 \cdot 19 \\
5-16\end{array}$ \\
\hline \multicolumn{4}{|c|}{ Significance of difference } \\
\hline $\mathrm{p}$ & 0.01 & $<0.01$ & $>0.1$ \\
\hline
\end{tabular}

Table II gives the results of part 2 of the study and shows that the change in core temperature postprandially and the ratio of postprandial to initial flow were significantly different between the groups $(\mathrm{p}<0.01)$ while the change in heart rate was not.

\section{Discussion}

Thermoregulatory responses are controlled at both the spinal and peripheral levels within the nervous system as well as at the higher integrative centres of the hypothalamus. Thus local cooling or heating of the preoptic and anterior hypothalamic regions may elicit the same reactions (cutaneous vasoconstriction and shivering or vasodilatation and sweating) that occur during exposure to cold or heat ${ }^{7}{ }^{8}$; but the final responses from these centres will be modified by signals from peripheral thermal sensors. ${ }^{9}$ The relative contributions of changes in central and peripheral temperatures to the responses of thermoregulatory sweating and vasodilatation have been evaluated ${ }^{10}{ }^{11}$; these responses $(R)$ are linearly related to core temperature according to the equation

$\mathrm{R}=\mathrm{a}_{\mathbf{1}}$ core temperature $+\mathrm{a}_{\mathbf{2}}$ mean skin temperature $+\mathrm{b}$

where $a_{1} / a_{2} \approx 8$. This relation is relevant to analysis of the data in the present study, since to examine the possibility of a disturbance in the central thermoregulatory responsiveness of these patients account must be taken of the effect of differences in peripheral temperature between the patients and controls.

Table I shows that the mean initial peripheral flow of the patients was significantly less than that of controls. This correlates with the common clinical finding of cold, blue extremities in these patients and is doubtless related to their low core temperatures and low metabolic rates. The mean initial core temperature of the patients was much lower than that of the controls.

Though the mean rise in core temperature necessary to initiate dilatation was significantly higher for the patients with anorexia, the actual central and peripheral temperatures at

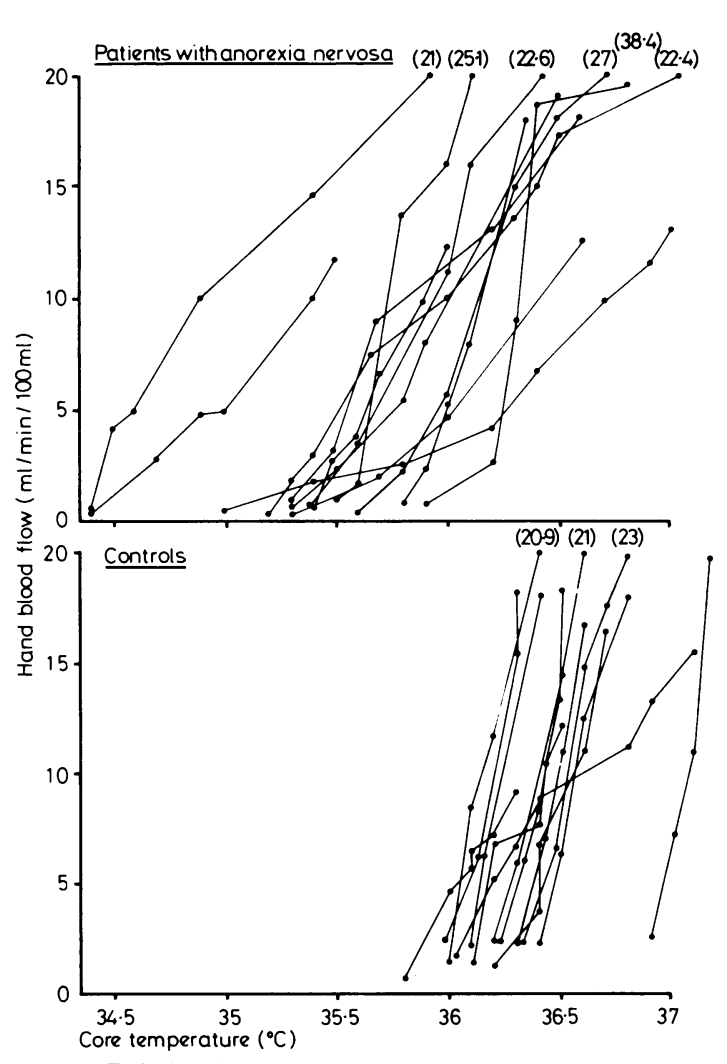

FIG 1-Relation between core temperature and hand blood flow in patients with anorexia nervosa and control subjects.

which vasodilatation occurred were both significantly lower in the patients than the controls. Figure 1 shows the relation between core temperature and peripheral flow in both groups obtained from the results of part 1 of the study. This indicates that, while the response is more variable in anorectic patients, there is a definite shift of the relation to the left in this group compared with controls. Thus at an arbitrary peripheral flow of $8 \mathrm{ml} / \mathrm{min} / 100 \mathrm{ml}$ table I shows that the malnourished group had significantly lower mean core and peripheral temperatures than the controls. The slopes of the responses $(\alpha)$ normalised to a flow of $8 \mathrm{ml} / \mathrm{min} / 100 \mathrm{ml}$ and a mean skin temperature of $33^{\circ} \mathrm{C}$, however, were not significantly different between the two groups.

The possibility that this shift in response may be the result of an exaggerated peripheral effect on dilatation seems unlikely since Freyschuss et $a l^{12}$ showed that patients with anorexia exhibit reduced thermoregulatory dilatation when exposed to indirect heating compared with controls.

No significant difference in the mean maximal flow rates was obtained for the two groups, in accordance with the findings of Gleeson and Moore. ${ }^{13}$ The significantly longer mean time from 
the onset of dilatation to half maximal flow observed in the anorectic group is probably explained by the lower flow rates at the time of vasodilatation in these patients and not, as has been suggested, ${ }^{14}$ by a more "sluggish" response. Table I and figure 2 show that thermoregulatory sweating occurred at significantly lower core and peripheral temperatures in the patients than the controls.

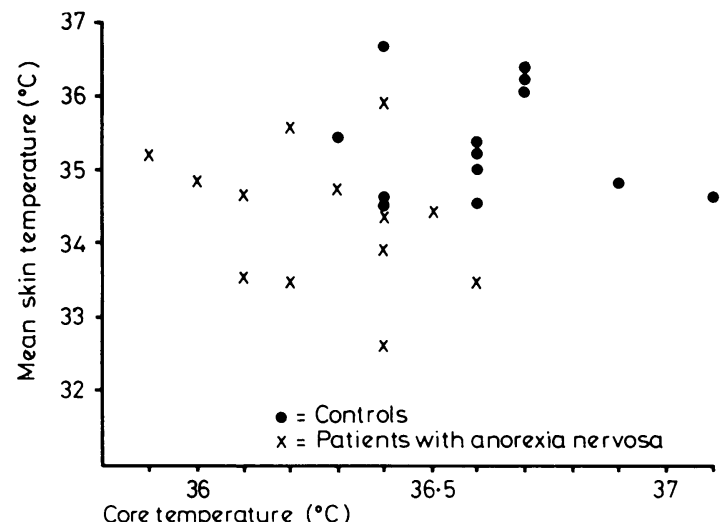

FIG 2-Core temperature and mean skin temperature at onset of forehead sweating in patients with anorexia nervosa and control subjects.

These observations provide evidence for a lowering of thermoregulatory vasodilator and sudomotor thresholds in anorexia nervosa, and indicate that these changes are probably mediated at a central level.

The results obtained in part 2 of the study (table II) were derived from the average core temperature, flow rate, and heart rate observed between the 60th and 90th minutes of the postprandial period. They confirm the earlier observation ${ }^{14}$ that ingestion of a high-energy meal provokes an abnormal increase in core temperature in anorectic patients. The increased thermic effect of glucose in patients with anorexia was described by Stordy et $a l^{15}$ and is probably related to the lower fasting concentrations of free fatty acids found in this group compared with normal subjects. ${ }^{16}$ We found no evidence, however, to support the suggestion of Wakeling and Russell ${ }^{14}$ that a raised thermal vasodilator threshold in anorectic patients may contribute to the observed postprandial rise in core temperature by blocking radiant heat loss. The mean ratio of postprandial to initial flow in the anorectic group was significantly greater than that in the control group. That this vasodilatation was thermally elicited is suggested by the lack of vasodilator responses of two of the patients, whose core temperature failed to rise above the central thresholds after the meal. No significant difference was apparent in the means of the postprandial changes in heart rate.

We believe that our interpretation provides a physiological basis for some of the physical features of anorexia nervosa and may rationalise some of the common symptoms reported by patients with the disease. Thus, although the low metabolic rates of these malnourished patients is undoubtedly the primary cause of their low body temperatures, the lowering of thresholds for thermoregulatory sweating and vasodilatation could clearly exacerbate and perpetuate this tendency towards hypothermia. A similar mechanism was proposed by Wenger $e t a l^{6}$ to account in part for the normal circadian lowering of body temperature at night. The common complaints of patients with anorexia nervosa that food induces feelings of excessive heat peripherally and sweating may also be ascribed to reduced thresholds of these responses triggered by an increased thermic effect of food. Tachycardia (another symptom often complained of) would also be more likely to occur in anorectic patients in warm surroundings after a meal. Finally, we are tempted to speculate that the sensation of intense internal heat reported by some anorectic patients after a meal may be a manifestation of the rise in core temperature towards a lowered central thermostat in a manner analogous to that in which the pyrogen-induced movement of the central thermostat away from a normal core temperature is considere ${ }^{17}{ }^{7}$ to produce a sensation of chill at the onset of a fever.

\section{References}

1 Wakeling A, DeSouza VFA, Beardwood CJ. Assessment of the negative and positive feedback effects of administered oestrogen on gonadotrophin release in patients with anorexia nervosa. Psychol Med 1977;7: 397-405.

2 Mecklenburg RS, Loriaux DL, Thompson RH, Anderson AE, Lipsett MB. Hypothalamic dysfunction in patients with anorexia nervosa. Medicine $1974 ; 53: 147-59$.

${ }^{3}$ Russell GFM. Anorexia nervosa: its identity as an illness and its treatment. In : Price JH, ed. Modern trends in psychological medicine. Vol 2. London: Butterworths, 1970:131-64.

4 Greenfield ADM. A simple water-filled plethysmograph for the hand or forearm with temperature control. F Physiol (Lond) 1954;123:62P.

${ }^{5}$ Palmes ED, Park CR. Cited by: Teichner WH. Assessment of mean body surface temperature. F Appl Physiol 1958;12:169-76.

${ }^{6}$ Wenger CB, Roberts MF, Stolwijk JAJ, Nadel ER. Nocturnal lowering of thresholds for sweating and vasodilatation. F Appl Physiol 1976;41: $15-9$

7 Hammel HT. Neurons and temperature regulation. In: Yamamoto WS, Brobeck JR, eds. Physiological controls and regulations. Philadelphia: WB Saunders, 1965:71-97.

${ }^{8}$ Hardy JD. The "set point" concept in physiological temperature regulation. In: Yamamoto WS, Brobeck JR, eds. Physiological controls and regulations. Philadelphia: WB Saunders, 1965:98-116.

9 Benzinger TH. The diminution of thermoregulatory sweating during cold reception at the skin. Proc Natl Acad Sci USA 1961;47:1683.

10 Wenger CB, Roberts MF, Stolwijk JAJ, Nadel ER. Forearm blood flow during body temperature transients produced by leg exercise. $\mathcal{F} A p p$ Physiol 1975;38:58-63.

${ }^{11}$ Nadel ER, Bullard RW, Stolwijk JAJ. Importance of skin temperature in the regulation of sweating. $\mathcal{F}$ Appl Physiol $1971 ; 31 ; 80-7$.

${ }^{12}$ Freyschuss U, Fohlin L, Thoren C. Limb circulation in anorexia nervosa. Acta Paediatr Scand 1978;67:225-8.

13 Gleeson C, Moore RE. Investigation of heat control in anorexia nervosa. Ir F Med Sci $1974 ; 143: 357 P$.

14 Wakeling A, Russell GFM. Disturbances in the regulation of body temperature in anorexia nervosa. Psychol Med 1970;1:30-9.

15 Stordy BJ, Marks V, Kalncy RS, Crisp AH. Weight gain, thermic effect of glucose and resting metabolic rate during recovery from anorexia nervosa. Am f Clin Nutr 1977;30:138-46

${ }^{16}$ Jequier E, Pittet PH, Gygax PH. Thermic effects of glucose and thermal body insulation in lean and obese subjects: a calorimetric approach. Proc Nutr Soc 1978;37:45-53.

17 Guieu JD, Hellon RF. The chill sensation in fever. Pfluegers Arch 1980; 384:103-4.

(Accepted 14 August 1980)

ONE HUNDRED YEARS AGO SIR,-I attended a patient for about a fortnight, and, as her husband was out of work, she applied for parish relief, which was granted. Next day, the parish medical officer told her that, as she had accepted parish relief, she would be compelled to have him to attend her. She told him that I was in attendance, and that, as she was now convalescing, she did not wish to change. He told her that there was no alternative, and that she must discharge me and submit to his treatment. He never communicated with me in any way, but took the case and kept it. Was this in accordance with medical etiquette? and does the fact of a person's accepting temporary parish relief compel that person to have the parish doctor nolens volens?-I remain, yours, etc., Delta.

** Delta's patient having applied for parochial relief, it was incumbent on the relieving officer to give an order to the district medical officer to visit, take charge, and report on the nature of the case. So far, we consider that the medical officer was strictly en règle; but, having been informed that the poor woman had been under the care of another medical man, it would have been but an act of courtesy if he had allowed the case to remain under his treatment, or had communicated with him thereon. This, however, he was not required to do if he did not care to give himself the trouble. (British Medical Fournal, 1880.) 